\title{
Time relations of squirrel monkey (Saimiri sciureus) sperm capacitation and ovum maturation in an in-vitro fertilization system
}

\author{
T. J. Kuehl and W. R. Dukelow
}

Endocrine Research Unit, Michigan State University, East Lansing, Michigan 48824, U.S.A.

\begin{abstract}
Summary. First polar body expulsion in the squirrel monkey ovum occurred at an average of $13.1 \mathrm{~h}$ after hCG injection when observed in culture but could occur as early as $5 \mathrm{~h}$ after hCG. The mean time for extrusion of the second polar body was $4.7 \mathrm{~h}$ after insemination of the culture with freshly ejaculated spermatozoa $(16.3 \mathrm{~h}$ after hCG). The earliest time, and therefore also that of sperm capacitation, was $2 \mathrm{~h}$ after insemination. First cleavage occurred $16 \cdot 2 \mathrm{~h}$ after insemination.
\end{abstract}

\section{Introduction}

In recent years considerable progress has been achieved towards the successful in-vitro fertilization of human (Edwards, Bavister \& Steptoe, 1969; Soupart \& Strong, 1974, 1975; Lopata, Johnston, Hoult \& Speirs, 1980) and non-human primate ova (Johnson, Harrison \& Dukelow, 1972; Gould, Cline \& Williams, 1973; Kuehl \& Dukelow, 1975, 1979; Dukelow \& Kuehl, 1975) as well as for many common laboratory species. The present study was undertaken to determine the times for expulsion of first and second polar bodies for the squirrel monkey. The time for expulsion of the first polar body after hCG injection is taken to be the time required for maturation of the ovum. The time needed for sperm capacitation is taken to be somewhat less than the time for second polar body expulsion.

\section{Materials and Methods}

Adult monkeys (Saimiri sciureus) were classified by karyotype and export point of origin and were of the Colombian (Leticia, Colombia; 6 acrocentric pairs of chromosomes) and Bolivian (Santa Cruz, Bolivia; 6 acrocentric pairs of chromosomes) types (Ariga, Dukelow, Emley \& Hutchinson, 1978).

To avoid the season of lowered ovarian response to gonadotrophins (Harrison \& Dukelow, 1973) all trials were conducted from October to June. Follicular growth was induced by a regimen of 4 days of FSH ( $1 \mathrm{mg} /$ day) followed by a single injection of 500 i.u. hCG (Dukelow, 1970). The minimum effective dose of hCG to induce ovulation has been shown to be between 100 and 250 i.u. (Dukelow, 1979). The techniques of laparoscopic ovum recovery, semen collection and in-vitro fertilization have previously been described (Kuehl \& Dukelow, 1975, 1979).

In a previous series of ovum aspirations, $10 / 27(37.0 \%)$ ova recovered $10 \mathrm{~h}$ or less after hCG injection had already matured and mature ova were recovered as early as $5 \mathrm{~h}$ after hCG. Obviously some of these may have begun the maturation process in response to an endogenous 
LH release prior to hCG administration. Since a primary objective of the present studies was to determine the time requirement for second polar body extrusion after insemination in vitro, follicular aspirations were carried out 9-11 h after hCG when a greater proportion of the oocytes would be at the first polar body (mature) stage. The time of first polar body extrusion relative to the hCG injection was examined in oocytes that had not reached the first polar body stage. Sequential observations of 35 cultured follicular oocytes were carried out at intervals of $3 \mathrm{~h}$ or less, beginning after follicular aspiration. Maturation was considered to be complete midway between the observations bracketing the first polar body expulsion by any given ovum. The appearance of a second polar body was taken as presumptive evidence of fertilization. To determine the time of second polar body extrusion, sequential observations of 25 cultured ova were continued at intervals of $3 \mathrm{~h}$ or less. Three additional ova were observed sequentially at intervals of 2.5 to $11.5 \mathrm{~h}$. Fertilization was considered to have occurred by the midpoint between consecutive observations bracketing the second polar body expulsion.

Three of the ova progressed from the second polar body to the 2-cell stage during the period of sequential observations and the limited data on the cleavage of these ova were included.

In addition to calculating the approximate times of maturation, fertilization and cleavage, data were collected for each ovum relating to the earliest and latest possible times when these developmental events could have occurred.

\section{Results}

The results are shown in Table 1. Ova from which the first polar body had already been extruded were sometimes recovered from the follicle at the time of follicular aspiration.

Table 1. Mean ( \pm s.d.) times of expulsion of first and second polar bodies from squirrel monkey oocytes after gonadotrophin treatment, laparoscopic follicular recovery and in-vitro fertilization

\begin{tabular}{lccc}
\hline & & \multicolumn{2}{c}{ Developmental time $(\mathrm{h})$} \\
\cline { 3 - 4 } & No. of eggs & After hCG & After insemination \\
\hline $\begin{array}{l}\text { First polar body } \\
\quad \text { (maturation) }\end{array}$ & 35 & $13 \cdot 1 \pm 2 \cdot 7$ & \\
$\begin{array}{l}\text { Second polar body } \\
\quad \text { fertilization) }\end{array}$ & 28 & $16.3 \pm 2 \cdot 7$ & $4 \cdot 7 \pm 2.6$ \\
First cleavage & 3 & $29.2 \pm 8 \cdot 8$ & $16.2 \pm 7.6$ \\
\hline
\end{tabular}

Because of the possibility of endogenous factors triggering ovum maturation, the times of second polar body extrusion and cleavage were examined in relation to the time of insemination rather than hCG administration and these results are shown in Table 1. The mean time of second polar body extrusion after insemination $(4.7 \mathrm{~h})$ would be a little more than the time required for capacitation under in-vitro conditions for squirrel monkey spermatozoa. The shortest period required, after addition of spermatozoa to the system, for an ovum to extrude the second polar body was $2.0 \mathrm{~h}$ for an ovum that had a single polar body $1.3 \mathrm{~h}$ after insemination and 2 polar bodies $0.7 \mathrm{~h}$ later. Of 28 ova, $24(85.7 \%)$ exhibited second polar body extrusion within one standard deviation of the mean $(4 \cdot 7 \mathrm{~h})$.

Cleavage to the two-cell stage occurred at an average time of $16 \cdot 2 \pm 7.6 \mathrm{~h}$ after insemination (Table 1). The ranges for the earliest and latest possible times of this first cleavage for these three ova were $6 \cdot 2-10 \cdot 8,10 \cdot 9-22.3$ and $22.4-24.8 \mathrm{~h}$. 


\section{Discussion}

All workers using the squirrel monkey as a model for human in-vitro fertilization work have had to rely on the use of exogenous hormones to induce follicular growth and ovum maturation because of the lack of menstrual cycles and overt signs of sexual receptivity in this species. Accordingly, knowledge of the time of maturation relative to exogenous administration of hCG is important to allow maximum opportumity for sperm penetration during culture. In the present studies, with ovum recovery at 9-11 h after hCG, non-matured ova extruded the first polar body at $13 \cdot 1 \mathrm{~h}$. This value can be contrasted with a value of $26 \mathrm{~h}$ for man (Edwards \& Steptoe, 1975). In the present study, first polar body extrusion occurred during culture at $9.0-17.3 \mathrm{~h}$ after administration of hCG.

The times obtained for extrusion of the second polar body after insemination of eggs in vitro are comparable to the 3-4 h sperm capacitation time reported for rhesus macaques (Macaca mulatta) by Marston \& Kelly (1968) after in-vivo timed-mating studies. Similar results for sperm capacitation times (3-7 h) have been reported for man (Soupart \& Strong, 1974; Lopata, McMaster, McBain \& Johnston, 1978).

The present values for time of maturation and second polar body extrusion are at the lower end of the range of previously reported values for the stages of squirrel monkey embryonic development (Kuehl \& Dukelow, 1979). This reflects the greater frequency of sequential observations in the present studies and thus more accurate determination of the time of polar body extrusion.

This work was supported by research grants from the March of Dimes Birth Defects Foundation and the National Institutes of Health.

\section{References}

Ariga, S., Dukelow, W.R., Emley, G.S. \& Hutchinson, R.R. (1978) Possible errors in identification of squirrel monkeys (Saimiri sciureus) from different South American points of export. J. med. Primatol. 7, 129-135.

Dukelow, W.R. (1970) Induction and timing of single and multiple ovulation in the squirrel monkey (Saimiri sciureus). J. Reprod. Fert. 22, 303-309.

Dukelow, W.R. (1979) Human chorionic gonadotropin: induction of ovulation in the squirrel monkey. Science, N.Y. 206, 234-235.

Dukelow, W.R. \& Kuehl, T.J. (1975) In-vitro fertilization of nonhuman primates. In La Fecondation, pp. 67-80. Ed. C. Thibault. Masson, Paris.

Edwards, R.G. \& Steptoe, P.C. (1975) Induction of follicular growth, ovulation and luteinization in the human ovary. J. Reprod. Fert., Suppl. 22, 121-163.

Edwards, R.G., Bavister, B.D. \& Steptoe, P.C. (1969) Early stages of fertilization in vitro of human oocytes. Nature, Lond. 221, 632-635.

Gould, K.G., Cline, E.M. \& Williams, W.L. (1973) Observations on the induction of ovulation and fertilization in vitro in the squirrel monkey (Saimiri sciureus). Fert. Steril. 24, 260-268.

Harrison, R.M. \& Dukelow, W.R. (1973) Seasonal adaptation of laboratory-maintained squirrel monkeys (Saimiri sciureus). J. med. Primatol. 2, 277-283.

Johnson, M.P., Harrison, R.M. \& Dukelow, W.R. (1972)
Studies on oviductal fluid and in-vitro fertilization in rabbits and nonhuman primates. Fedn Proc. Fedn Am. Socs. Exp. Biol. 31, 269.

Kuehl, T.J. \& Dukelow, W.R. (1975) Fertilization in vitro of Saimiri sciureus follicular oocytes. $J$. med. Primatol. 4, 209-216.

Kuehl, T.J. \& Dukelow, W.R. (1979) Maturation and in vitro fertilization of follicular oocytes of the squirrel monkey (Saimiri sciureus). Biol. Reprod. 21, 545556.

Lopata, A., McMaster, R., McBain, J.C. \& Johnston, W.I.H. (1978) In-vitro fertilization of preovulatory human eggs. J. Reprod. Fert. 52, 339-342.

Lopata, A., Johnston, I.W.H., Hoult, I.J. \& Speirs, A.I. (1980) Pregnancy following intrauterine implantation of an embryo obtained by in-vitro fertilization of a preovulatory egg. Fert. Steril. 33, 117-120.

Marston, J.H. \& Kelly, W.A. (1968) Time relationships of spermatozoa penetration into the egg of the rhesus monkey. Nature, Lond. 217, 1073-1074.

Soupart, P. \& Strong, P.A. (1974) Ultrastructural observations on human oocytes fertilized in vitro. Fert. Steril. 25, 11-44.

Soupart, P. \& Strong, P.A. (1975) Ultrastructural observations on polyspermic penetration of zonapellucida-free human oocytes inseminated in vitro. Fert. Steril. 26, 523-537. 